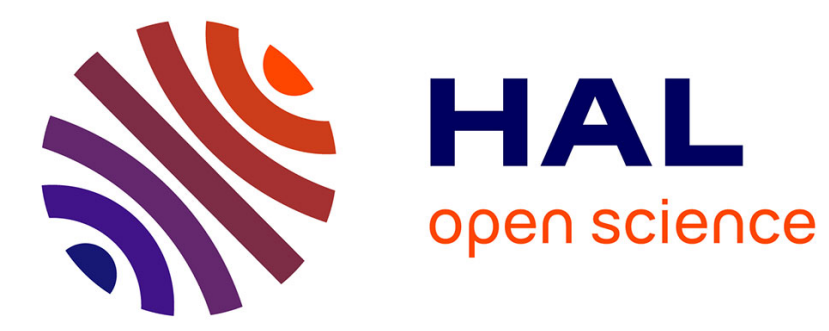

\title{
DILATATION FIELD OF A REGULAR HEXAGONAL NETWORK OF MISFIT DISLOCATIONS. APPLICATION TO (lll)Si//(lll)CoSi2
}

A Bouzaher, J.-L. Verger-Gaugry, R Bonnet

\section{- To cite this version:}

A Bouzaher, J.-L. Verger-Gaugry, R Bonnet. DILATATION FIELD OF A REGULAR HEXAGONAL NETWORK OF MISFIT DISLOCATIONS. APPLICATION TO (1ll)Si//(ll1)CoSi2. Scripta Metallurgica et Materialia, 1992, 26 (7), pp.1107-1112. 10.1016/0956-716X(92)90238-A . hal-03133833

\section{HAL Id: hal-03133833 \\ https://hal.science/hal-03133833}

Submitted on 15 Feb 2021

HAL is a multi-disciplinary open access archive for the deposit and dissemination of scientific research documents, whether they are published or not. The documents may come from teaching and research institutions in France or abroad, or from public or private research centers.
L'archive ouverte pluridisciplinaire HAL, est destinée au dépôt et à la diffusion de documents scientifiques de niveau recherche, publiés ou non, émanant des établissements d'enseignement et de recherche français ou étrangers, des laboratoires publics ou privés. 


\title{
DILATATION FIELD OF A REGULAR HEXAGONAL NETWORK OF MISFIT DISLOCATIONS. APPLICATION TO ( 111 ) Si // ( 111 ) $\mathrm{CoSi}_{2}$
}

\author{
A. Bouzaher ${ }^{\ddagger}$, J.-L. Verger-Gaugry $y^{\ddagger}$ and R. Bonnet ${ }^{\ddagger \dagger}$ \\ ¥ LTPCM/ENSEEG/INPG (CNRS UA 29), BP 75, Domaine Universitaire, 38402 Saint \\ Martin d'Hères, France \\ $\dagger$ National Center for Electron Microscopy, Lawrence Berkeley Laboratory, Bldg. 72 \\ Lawrence Berkeley Laboratory, Bldg. 72, University of California, Berkeley, CA 94720, \\ USA.
}




\section{Introduction}

Diffusion phenomena under stress control the movements of misfit dislocations at high temperatures, e.g., $[1,2]$. For a better understanding of the diffusion paths of vacancies and atomic species on each side of the interface, it is necessary to determine all the elastic dilatation field $\theta$ since these paths are orthonormal curves to equi-dilatation surfaces. In addition, elastic interactions between all linear interfacial defects must be taken into account for an accurate description of $\theta$. A brief review of works involving the elastic fields of interfacial dislocations with a non planar deformation field shows in fact that no solutions exist yet in the literature for $\theta$, even for the simplest case of a regular hexagonal network of misfit dislocations, which is in practise a common case observed in transmission electron microscopy, e.g., [3-6].

Since the first works $[7,8]$ on low angle boundaries forming hexagonal patterns of dislocations lying parallel to (111) or (001) planes of cubic crystals, some authors have been faced with the problem of determining the stress fields and energies of dislocations visible along grain boundaries [9-12]. On the other hand, for a regular hexagonal pattern of misfit dislocations along an interphase boundary, the elastic field along the interface has not yet been obtained, except a formal solution derived from a double Fourier series analysis [13]. In this reference, to which the reader has to refer for notations, two different elastically isotropic media are used. The displacement field $\mathbf{u}$ is assumed to be biperiodic with two period vectors $\mathbf{O A}=\mathbf{a}$ and $\mathbf{O C}=\mathbf{c}$, as shown in Fig. 1, where $\mathrm{O}$ is the center of the hexagon UVWRSZU. However, only a formal result was presented because :

(i) the problem was found untractable for the most common case of any two media. Indeed, an algebraical inversion of a linear system of 12 equations with 12 unknowns, equ. (26) in [13], could not be achieved.

(ii) the non zero expressions of the right parts of the 12 above mentioned equations

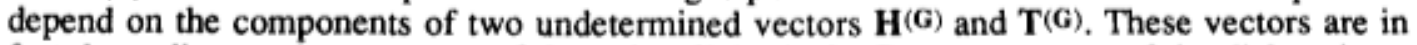
fact depending on the geometry of the unit cell $(\mathbf{a}, \mathbf{c})$, the Burgers vectors of the dislocations. and the way to place the Cartesian frame $\mathrm{Ox}_{1} \mathrm{x}_{2} \mathrm{x}_{3}$ relative to a hexagonal cell.

The aim of the present note is first to present a definitive answer for point (i), while for point (ii) and for the geometry of Fig. 1 the vectors $\mathbf{H}^{(\mathbf{G})}$ and $\mathbf{T}^{(G)}$ will be given. As a result, the complete displacement field can also be obtained. The volumic dilatation field will 
be presented explicitly versus the geometrical parameters of a regular hexagonal network. A numerical application will be made for the volumic dilatation $\theta$ along the interphase boundary of a model system $\mathrm{Si} / \mathrm{CoSi}_{2}$ interface, which has been subjected to numerous investigations e.g. $[5,14,15]$.

\section{Explicit solutions for eq. (26) in ref. $[13]$}

Let us first answer to point (ii) mentioned above, for convenience.

For simplification, the Cartesian frame $\mathrm{Ox}_{1} \mathrm{x}_{2} \mathrm{x}_{3}$ described in [13] will be centered in $\mathrm{O}$ so that $\mathbf{H}^{(\mathbf{G})}=0$, since the three components of the interfacial relative displacement are odd functions with $x_{1}$ and $x_{3}$. The geometry of a regular hexagon UVWRSZ is characterized by

- two period vectors a and $\mathbf{c}$ making an angle (a,c) equal to 60 degrees, with $|\mathbf{a}|=|\mathbf{c}|$.

- a point $\mathrm{U}$ such that $\mathrm{OU}=(\mathbf{a}+\mathbf{c}) / 3$.

The elastic field also depends on the Burgers vectors of the misfit dislocations. These latter have their lines oriented clockwise in Fig. 1. For practical purposes, only two of them need to be considered, our choice being the segments $\mathrm{ZU}$ and UV with Burgers vectors $\mathbf{b}(\mathrm{zu})$ and $\mathbf{b}($ uv).

The vector $\mathbf{T}(\mathbf{G})$, with components $\left(\mathrm{T}_{1}, \mathrm{~T}_{2}, \mathrm{~T}_{3}\right)$, has been obtained from cumbersome integrations [16]. It depends on the non-zero reciprocal vector $\mathbf{G}(\mathrm{m}, \mathrm{n})$, where $\mathrm{m}, \mathrm{n}$ are algebraic integers. The result is the following :

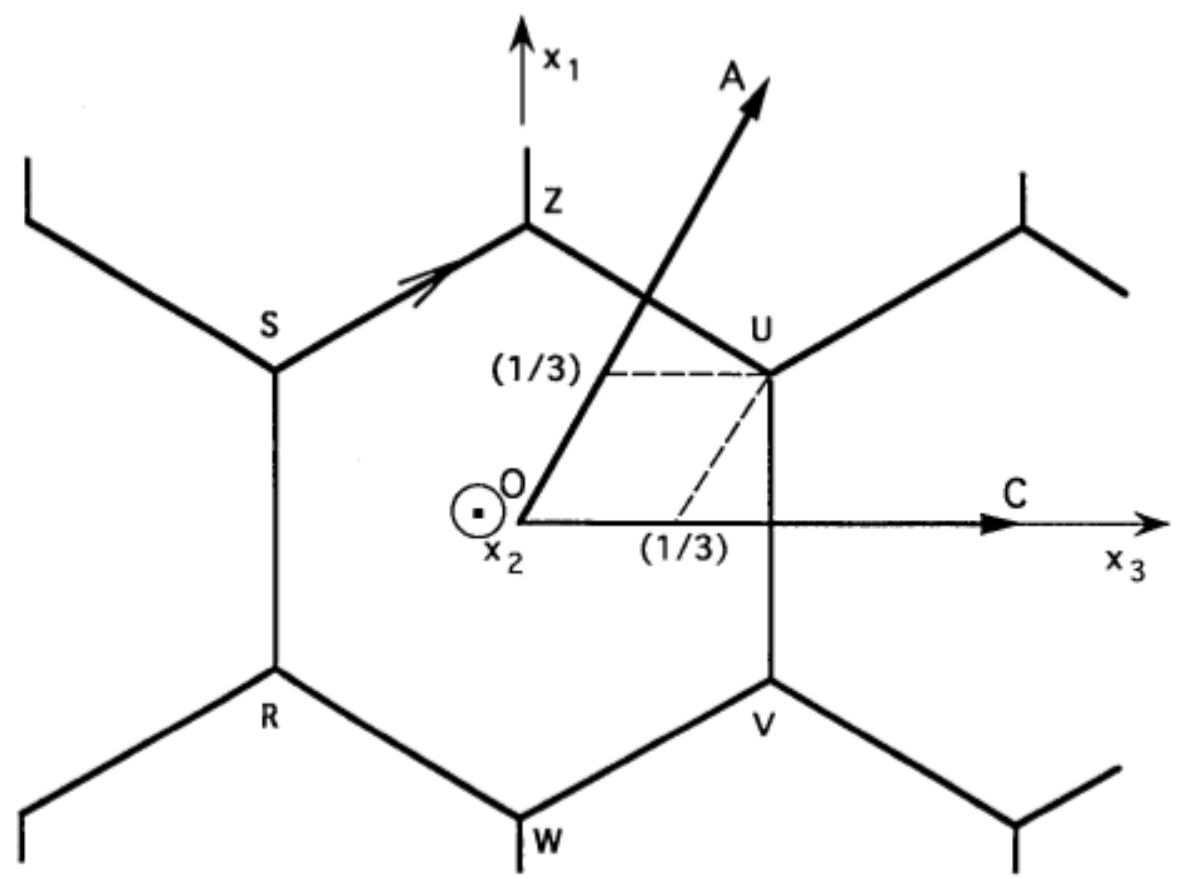

Figure 1: A regular hexagonal network of misfit dislocations oriented clockwise UVWRSZ around the center $\mathrm{O}$ of a hexagon. $\mathbf{O A}$ and $\mathbf{O C}$ are the period vectors. The Cartesian frame used is $\mathrm{Ox}_{1} \mathrm{x}_{2} \mathrm{x}_{3}$ with $\mathrm{Ox}_{2}$ normal to the interface towards medium + , and $\mathrm{Ox}_{3} / / \mathbf{O C}$. The angle (OC,OA) is 60 degrees. 
for $m+n \neq 0$ and $n-2 m \neq 0$ and $m-2 n \neq 0$

$$
\mathbf{T}^{(\mathbf{G})}=\frac{3 \sin \left[\frac{2 \pi}{3}(m+n)\right]}{\pi^{2}(m+n)}\left[\frac{b^{(\mathrm{ZU})}}{n-2 m}+\frac{\mathbf{b}^{(\mathrm{UV})}}{m-2 n}\right]
$$

for $m+n=0$ and $m \neq 0$

$$
\mathbf{T}^{(\mathbf{G})}=\frac{1}{3 \pi \mathrm{m}}\left[\mathbf{b}^{(\mathrm{ZU})}-\mathbf{b}^{(\mathrm{UV})}\right]
$$

for $\mathrm{n}-2 \mathrm{~m}=0$ and $\mathrm{m}+\mathrm{n} \neq 0$

$$
\mathbf{T}^{(\mathbf{G})}=\frac{(-1)^{(\mathrm{n}+1)}}{\pi(\mathrm{m}+\mathrm{n})} \mathbf{b}^{(\mathrm{ZU})}
$$

for $\mathrm{m}-2 \mathrm{n}=0$ and $\mathrm{m}+\mathrm{n} \neq 0$

$$
\mathbf{T}^{(\mathbf{G})}=\frac{(-1)^{(m+1)}}{\pi(m+n)} \mathbf{b}^{(\mathrm{UV})}
$$

The validity of these expressions has been checked numerically in computing, for some points inside the hexagon, the interfacial relative displacement of the crystals by two different ways : (i) from the limiting boundary condition (linear variation with $\mathrm{x}_{1}$ and $\mathrm{x}_{3}$ ); (ii) from the sum of the double Fourier series involving the $T(\mathbf{G})$ 's.

Let us now turn to point (i). In eqs. (26) of [13], the unknowns are $A_{i}$ and $B_{i}$ $(\mathrm{i}=1,2,3)$, for each crystal + or -. In passing, let us correct a misprint in the 12 th eqs. (26) : the term $B_{3}^{-}$must be changed into $B_{1}^{-}$. The unknowns have been derived explicitly from the solution of the 12 linear equations, thanks to a formal algebra software :

$$
\begin{array}{ll}
A_{1}^{+}=s_{1} T_{2} /(G \Delta) & A_{1}^{-}=A_{1}^{+} \\
A_{2}^{+}=-T_{2} /\left[\left(1+3-4 v^{+}\right)\right] & A_{2}^{-}=-T_{2} /\left[\left(k+3-4 v^{-}\right)\right] \\
A_{3}^{+}=s G_{3} T_{2} /(G \Delta) & A_{3}^{-}=A_{3}^{+} \\
B_{1}^{+}=-\left(p G_{3}^{2} T_{1}+q G_{1} G_{3} T_{3}+r G_{1}^{2} T_{1}\right) /\left(G^{2} \Delta\right) & B_{1}^{-}=-B_{1}^{+}-T_{1} \\
B_{2}^{+}=\left(G_{1} T_{1}+G_{3} T_{3}\right) /\left[G\left(1+3-4 v^{+}\right)\right] \quad B_{2}^{-}=\left(G_{1} T_{1}+G_{3} T_{3}\right) /\left[G\left(k+3-4 v^{-}\right)\right] & \\
B_{3}^{+}=-\left(p G_{1}^{2} T_{3}+q G_{1} G_{3} T_{1}+r G_{3}^{2} T_{3}\right) /\left(G^{2} \Delta\right) & B_{3}^{-}=-B_{3}^{+}-T_{3} \\
\text { where } \quad k=\mu-/ \mu^{+} & \\
\quad p=k\left(3+k-4 v^{-}\right)\left[1+k\left(3-4 v^{+}\right)\right] & \\
\quad q=2 k\left[1-v^{-}-3 v^{+}+4 v^{-} v^{+}+k\left(-1+3 v^{-}+v^{+}-4 v^{-} v^{+}\right)\right] & \\
r &
\end{array}
$$




$$
\begin{aligned}
& s=2 k(1+k)\left(2-3 v^{-}-3 v^{+}+4 v^{-} v^{+}\right) \\
& \Delta=(1+k)\left(3+k-4 v^{-}\right)\left[1+k\left(3-4 v^{+}\right)\right]=p(1+k) / k
\end{aligned}
$$

The above solutions for $A_{i}$ and $B_{i}(i=1,2,3)$ have been reinserted into the $12 \times 12$ system for the 12 equalities to be checked algebraically. Note that expressions (5-16) are valid whatever be the geometry of the hexagonal network, while expressions (1-4) are only specific to Fig. 1.

\section{The dilatation field_surrounding_a_regular_ hexagonal_network of misfit dislecations}

The dilatation field is defined by the classical formula [17]:

$$
\theta=\frac{\partial \mathrm{u}_{1}}{\partial \mathrm{x}_{1}}+\frac{\partial \mathrm{u}_{2}}{\partial \mathrm{x}_{2}}+\frac{\partial \mathrm{u}_{3}}{\partial \mathrm{x}_{3}}
$$

The derivatives are calculated from the expressions of the displacements [13] in which the $A_{i}$ and $B_{i}$ 's to be used are given, for each medium, by our expressions (1-16). The result shows that, for a given medium, $\theta$ only depends on the ratio $k$ and on the Poisson's coefficient of the medium. Putting the convenient superscript + or - to appropriate symbols,

$\theta=4 \pi(1-2 v) \operatorname{sign}\left(\mathrm{x}_{2}\right) \sum_{D} \mathrm{G}\left\{\mathrm{B}_{2} \cos \left\{2 \pi\left(\mathrm{G}_{1} \mathrm{x}_{1}+\mathrm{G}_{3} \mathrm{x}_{3}\right)\right]+\mathrm{A}_{2} \sin \left[2 \pi\left(\mathrm{G}_{1} \mathrm{x}_{1}+\mathrm{G}_{3} \mathrm{x}_{3}\right)\right]\right\} \mathrm{e}^{\left(-2 \pi \mathrm{G}\left|\mathrm{x}_{2}\right|\right)}$

with $\operatorname{sign}\left(\mathrm{x}_{2}\right)=+1$ for medium + , and -1 for medium -. Series (18) converges for non zero $\mathrm{x}_{2}$, because of the exponential term. However, just at the interface $\left(\mathrm{x}_{2}=0\right)$, the series diverges because of an interfacial discontinuity of $\theta$.

Series (18) becomes more simple if the Burgers vectors are parallel to the interface. In this case, if the edge and screw components of the dislocation segment UV are respectively denoted $b_{e}$ and $b_{s}$, the components of the Burgers vectors involved in expressions (1-4) are

$$
\mathbf{b}^{(\mathrm{zu})}=1 / 2\left[\left(\mathrm{~b}_{\mathrm{s}}+\mathrm{b}_{\mathrm{e}} \sqrt{3}\right), 0,\left(-\mathrm{b}_{\mathrm{s}} \sqrt{3}+\mathrm{b}_{\mathrm{e}}\right)\right] \quad \text { and } \quad \mathbf{b}^{(\mathrm{uv})}=\left[\mathrm{b}_{\mathrm{s}}, 0, \mathrm{~b}_{\mathrm{e}}\right]
$$

then $T_{2}=0$ and consequently $A_{2}=0$. As a result, for medium +

$$
\theta^{+}=\frac{4 \pi\left(1-2 v^{+}\right)}{\left(\begin{array}{l}
1 \\
k
\end{array}+3-4 v^{+}\right)} \sum_{D}\left\{\left(G_{1} T_{1}+G_{3} T_{3}\right) \cos \left[2 \pi\left(G_{1} x_{1}+G_{3} x_{3}\right)\right]\right\} e^{\left(-2 \pi \mathrm{Gx}_{2}\right)}
$$

The same formula applies to medium -, except some minor changes $\left(v^{+}\right.$into $v^{-} ; 1 / k$ into $k ; 4 \pi$ into $-4 \pi ;-2 \pi \mathrm{G}$ into $+2 \pi \mathrm{G})$.

Only the dilatation field $\theta$ towards $\mathrm{x}_{2}>0$ needs to be computed. $\theta$ in $\left(\mathrm{x}_{1},-\mathrm{x}_{2}, \mathrm{x}_{3}\right)$ is readily derived from $\theta^{+}$in the point $\left(\mathrm{x}_{1}, \mathrm{x}_{2}, \mathrm{x}_{3}\right)$, since 


$$
\theta^{-}=-\frac{\mu^{-}\left(1-2 v^{-}\right)\left\lfloor\mu^{-}+\mu^{+}\left(3-4 v^{+}\right)\right\rfloor}{\mu^{+}\left(1-2 v^{+}\right)\left[\mu^{+}+\mu^{-}\left(3-4 v^{-}\right)\right]} \theta^{+}
$$

As a result, for a grain boundary, the dilatation is an odd function with $\times_{2}$.

\section{Application to $\mathrm{Si} / \mathrm{CoSi2}$}

Formula (20) has been applied to the regular hexagonal network of $1 / 6<112>$ Si edge misfit dislocations as observed in [5] for the interface $\mathrm{Si} / \mathrm{CoSi} 2$, in order to have a quantitative idea of the change in the dilatation on either side of the interface.

The orientation relationship of both crystals is the "heterotwin" orientation [5], for which (111)CoSi2/(111)Si. The silicon is chosen towards $\mathrm{x}_{2}>0$. The data are the following :

lattice parameters [18]: $\mathrm{Si}=0.54309 \mathrm{~nm} ; \mathrm{CoSi}_{2}=0.5356 \mathrm{~nm} ; \mathrm{b}_{\mathrm{e}}=-0.2217 \mathrm{~nm} ; \mathrm{b}_{\mathrm{s}}=0$. misfit $\varepsilon=0.0145$; the periods $|\mathbf{a}|=|\mathrm{c}|$ were calculated as equal to $\left|\mathrm{b}_{\mathrm{e}}\right| / \varepsilon=15.6 \mathrm{~nm}$.

The elastic constants were computed following Appendix 2 of [19], from anisotropic Cij given in [17] for $\mathrm{Si},[20]$ for $\mathrm{CoSi}_{2}$ :

$$
\begin{aligned}
& \mu^{+}(\mathrm{Si})=6.61110^{10} \mathrm{~Pa} ; v^{+}=0.23 . \\
& \mu^{-}\left(\mathrm{CoSi}_{2}\right)=6.40210^{10} \mathrm{~Pa} ; v^{-}=0.34 .
\end{aligned}
$$

A FORTRAN programme was written to compute the variations of $\theta$ versus $\mathrm{x}_{2}$ in each medium $+(\mathrm{Si})$ and $-\left(\mathrm{CoSi}_{2}\right)$, when the running point is (i) along $\mathrm{Ox}_{2}$; curve 2 in Fig. 2; (ii) along a line parallel to $\mathrm{Ox}_{2}$ and passing through a triple node $\mathrm{Z}$; curve 1 in Fig. 2 . On the curves 1 and 2, only the open and filled dots were computed.The summation parameters $\mathrm{m}$ and $\mathrm{n}$ were risen up to 60 for good convergence of the double Fourier series. For the two curves, $\theta$ tends to practically zero at distances close to one period. Around the center $\mathrm{O}$ of a hexagon, and as expected from the lattice parameters, $\mathrm{Si}$ appears to be in tension and the

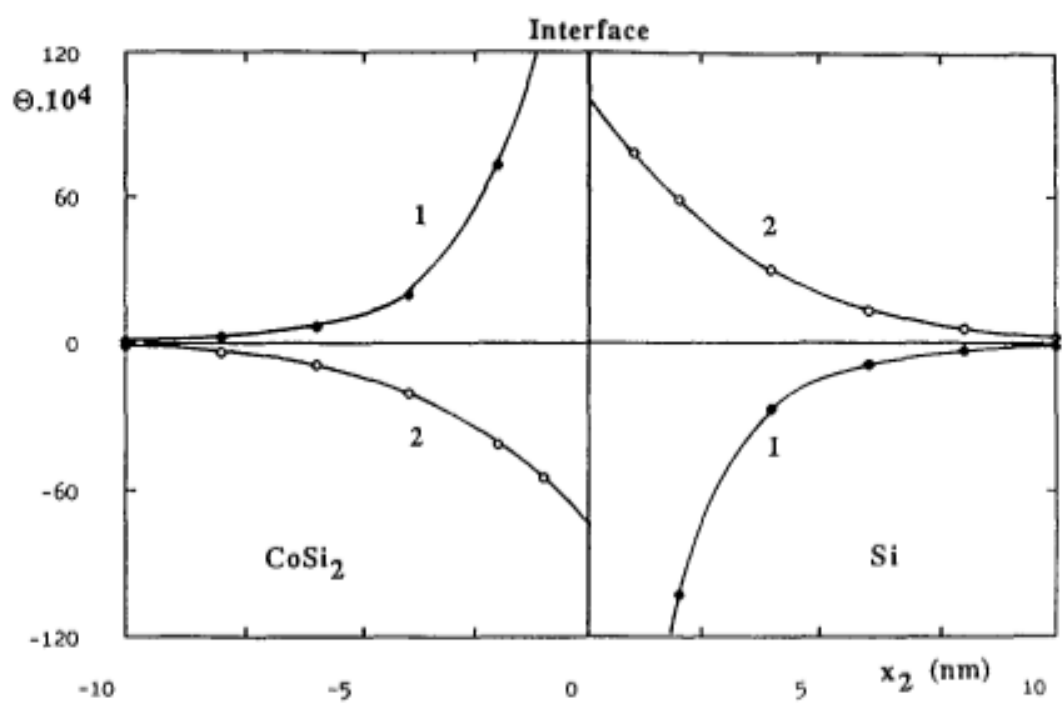

Figure 2: Change of the elastic dilatation $\theta$ in the vicinity of the interface $\mathrm{Si} / \mathrm{CoSi}_{2}$ with the distance $x_{2}$ to the boundary. Curve $1: \theta$ is varying from a triple node of the hexagonal network of dislocations. Curve $2: \theta$ is varying from the centre of a hexagon. 
other phase in compression. Close to the triple node $\mathrm{Z}$ the situation is reverse, $\theta$ diverging for $\mathrm{x}_{2}=0$. Note the large discontinuity of $\theta$ across the interface around $O$ (about 0.016 ) and the large $\theta$ gradient along the interface. Around $O$, its value is obtained from an extrapolation of the two part of curves 2 for $\mathrm{x}_{2}=0$. Relation (21) is here $\theta^{-}=-0.676 \theta^{+}$, which is valid except for $\mathrm{x}_{2}=0$.

\section{Summary}

The displacement field of any regular hexagonal pattern of misfit dislocations has been thorougly expressed from an analytical solution of a system of $12 \times 12$ linear equations given in [13]. The dilatation field $\theta$ induced by such a network has been derived explicitly under the form of a double Fourier series. For a grain boundary $\theta$ is an odd function with the coordinate $\mathrm{x}_{2}$ perpendicular to the interface whatever be the Burgers vectors. The solution has been applied to the case of an observed misfit dislocation network on the (111) $\mathrm{CoSi}_{2} /(111) \mathrm{Si}$ interface. Strong discontinuities of $\theta$ can be observed when crossing, or along, the interface.

\section{References}

[1] J. M. Howe, U. Dahmen, and R. Gronsky, Phil. Mag. A, 56, 31 (1987).

[2] J. M. Howe, and N. Prahbu, Acta Metall. Mater., 38, 881 (1990).

[3] A. Lasalmonie, and J. L. Strudel, Phil. Mag., 32, 937 (1975).

[4] G. Honjo and K. Tagi, in Current Topics in Materials Science, Ed. E. Kaldis (NorthHolland, Amsterdam), vol. 6, 195 (1980).

[5] C. W. T. Bulle-Lieuwma, A. H. van Ommen, and J. Hornstra, Mat. Res. Soc. Symp. Proc., 102, 377 (1988).

[6 L. A. Tietz, S. R. Summerfelt, and C. B. Carter, M. R. S. Proc. 159, 209 (1990).

[7] F.C. Franck, in Report of the Conference on Defects in Crystalline Solids, held at the H. H. Wills Physical Laboratory, University of Bristol., pub. by The Physical Society (July 1954).

[8] S. Amelinckx, in Dislocations and Mechanical Properties of Crystals, Int. Conf. held at Lake Placid, Sept. 6-8, Eds. J. C. Fisher, W. G. Johnston, R.Thompson (1957).

[9] J. L. Hokanson, and P. G. Winchell, Journal of Applied Physics,. 39, 3311 (1968).

[10] C. Rey and G. Saada, Phil. Mag., 33, 825 (1976).

[11] C. Rey and G. Saada, Journal de Physique, 38, 721 (1977).

[12] C. Rey and G. Saada, Acta Met, 27, 921 (1979).

[13] R. Bonnet, Phil. Mag., 44, 625 (1981).

[14] D. Cherns, G. R. Anstis, and J. L. Hutchinson, Phil. Mag. A, 42, 849 (1982).

[15] J. M. Gibson, R. T. Tung, J. M. Philips, and R. Hull, sup. to J. de Phys., 46, 369 (1985).

[16] A. Bouzaher, R. Bonnet and J. Mackenzie, internal report, LTPCM, Domaine Universitaire, BP75, 38402, Saint-Martin-d'Hères (France), nov. 1991.

[17] J. P. Hirth and J. Lothe, Theory of Dislocations, 2d ed., New-York: Wiley-Interscience (1982).

[18] B. D. Cullity, in Elements of X-Ray Diffraction, 2d ed., Addison-Wesley Pub., Inc, 507 (1978).

[19] R. Bonnet and A. J. Morton, Phil. Mag. A, 56,815 (1987).

[20] G. Guénin, M. Ignat and O. Thomas, J. Appl. Phys. 68, 6515 (1990). 